\title{
Genetic determinants of osteoporosis susceptibility in a female Ashkenazi Jewish population
}

Xiaohui Li, MD ${ }^{1,2}$, Sako Chen, $M D^{1}$, Vitaly Kantorovich, $M D^{1}$, Li S.C. Cheng, PhD ${ }^{1,2}$, Dan H. Cohn, PhD ${ }^{1,2}$, Jerome I. Rotter, $M D^{1,2}$, Huiying Yang, $M D, P h D^{1,2}$, and John S. Adams, $M D^{1,3}$

\begin{abstract}
Purpose: To determine the heritability of low bone mineral density (BMD) at the hip in Ashkenazi Jewish families.
Methods: BMD at hip was accessed by dual x-ray absorptiometry (DEXA) in 166 female subjects from 61 families. Variance component analysis was used to estimate genetic contributions. Results: We observed significant genetic contributions to age-adjusted BMD at the femoral neck as measured by heritability $0.67(P<0.0001)$. Conclusion: There is significant genetic determination in decreased BMD at the femoral neck in an Ashkenazi Jewish female population. These results warrant further gene mapping studies in this population to identify osteoporosis susceptibility loci. Genet Med 2004:6(1):33-37.
\end{abstract}

Key Words: osteoporosis, bone mineral density, genetics, heritability, familial correlation

Osteoporosis is a prevalent health problem that causes considerable morbidity and mortality. Presently, it is estimated that 10 million American women have osteoporosis and 18 million have low bone mass. ${ }^{1-3}$ This number is expected to increase at the rate of $2 \%$ per year well into the 21 st century. ${ }^{3}$ In the United States, more than 1.3 million osteoporotic fractures occur yearly with an estimated direct cost of 13.8 billion dollars. ${ }^{2-4}$ Although multiple environmental factors influence the development of osteoporosis, it is clear that the major determinant for the disease is oligogenetic control of the achievement of peak bone mass. ${ }^{5-15}$ Several twin studies have concluded that up to $85 \%$ of the variance in bone mineral density (BMD) in axial and appendicular skeleton is accounted for by genetic factors. ${ }^{6-11}$ In one of the largest studies, $85 \%$ and $81 \%$ of the BMD variation at the spine and hip, respectively, was attributed to heredity alone. ${ }^{10}$ The identification of genes that increase susceptibility to low BMD has significant diagnostic and therapeutic implications.

To identify loci that determine susceptibility to osteoporosis, we initiated a study of a single ethnic group, Ashkenazi Jews, where the incidence of osteoporosis is known to be high $(7.3 \%) .{ }^{16}$ Familial aggregation of osteoporosis in this ethnic group was previously reported with $45 \%$ of cases having a positive family history. ${ }^{17}$ In this latter study, the empiric risk of developing clinical osteoporosis was 33\% for a mother and $19 \%$ for a sister of a proband. In this present study, our aim was to estimate the heritability of low BMD at the hip in osteopo-

From ${ }^{1}$ Burns and Allen Research Institute and Divisions of Medical Genetics ${ }^{2}$ and Endocrinology, Diabetes and Metabolism ${ }^{3}$, Cedars-Sinai Medical Center and University of California, Los Angeles, California.

Xiaohui Li, MD, Division of Medical Genetics, Cedars-Sinai Medical Center, SSB 377, 8700 Beverly Boulevard, Los Angeles, CA 90048.

Received: September 8, 2003.

Accepted: October 17, 2003.

DOI: 10.1097/01.GIM.0000105742.39917.EF rosis families of Ashkenazi Jewish descent. The observed result, a significant heritability of BMD in the Ashkenazi Jewish families, increases the probability of identifying osteoporosis susceptibility genes in this population.

\section{MATERIALS AND METHODS}

\section{Subjects}

To minimize the variation in bone mass inherent between men and women, ${ }^{18-20}$ only female subjects were studied. Subjects comprised 166 Ashkenazi Jewish (AJ) females from 61 independent families. Among these subjects, 106 were from the proband generation, 50 from the offspring generation, and 10 from the parental generation. There were 61 Jewish probands, age 37 to 89 years (mean 61 years).

Subjects were recruited by the General Clinical Research Center staff after a proband was identified by a participating physician at Cedars-Sinai Medical Center. Institutional Review Board approval was obtained. Written informed consent was obtained by a physician investigator, and each participant was assigned a code number. Subjects were women $>20$ years of age. Probands were individuals with osteoporosis defined as (1) a BMD > 2.5 standard deviations (SD) below an idealized young adult mean or $\mathrm{T}$ score $>-2.5$ by dual $\mathrm{x}$-ray absorptiometry (DEXA) or (2) presence of low trauma fracture. Exclusionary criteria included vitamin D deficiency or intoxication, primary hyperparathyroidism, hyperthyroidism or untreated hypothyroidism, renal insufficiency, and current or previous prolonged exposure to immunosuppressive agents.

\section{Measurements}

All subjects underwent the clinical, biochemical, and densitometry assessment in the study. Information on smoking status, alcohol consumption, estrogen use, height, and weight was also collected. 


\section{Densitometry}

BMD at the left femoral neck was measured by DEXA on a QDR-2000 (Hologic, Inc., Waltham, MA) or a DPX-L densitometer (Lunar Corp., Madison, WI). The results were expressed as $\mathrm{T}$ and $\mathrm{Z}$ scores. The $\mathrm{T}$ score is a measure of deviation from the expected population mean of peak young adult bone mass. Clinically, it is used to predict fracture risk. The Z score is the measure of deviation from the expected population mean of age-matched referent population. All DEXA data were expressed as the mean \pm standard deviation (SD).

\section{Biochemical}

For each subject, blood samples $(90 \mathrm{~mL})$ and a $>2$-hour fasting, postfirst void urine was collected. Biochemical analyses included serum measurement of creatinine, calcium, albumin, magnesium, alkaline phosphatase, thyroid-stimulating hormone, and urine measurement of calcium and creatinine, by automated methods. Serum 25-hydroxyvitamin D, iPTH, osteocalcin, bonespecific alkaline phosphatase, and urine $\mathrm{N}$-telopeptide levels were also determined. ${ }^{21}$ All samples from a single pedigree were assayed together to avoid interassay variation. All information, samples, and data were identified by a code number; laboratory investigators were blinded to phenotypic status.

\section{Statistical analysis}

\section{Adjustment of BMD-related traits}

In order to assess the genetic influence of BMD, we adjusted $\mathrm{BMD}$ by nongenetic risk factors that may influence BMD, including age, body mass index [BMI, weight $(\mathrm{Kg})$ divided by the squares of height $(\mathrm{M})$ ], smoking status, alcohol consumption, estrogen usage, and measured biochemical variables. Because there were correlations between subjects within a family, generalized estimating equations (GEEs) with GENMOD were used to analyze these data for both univariate and multivariate analysis (SAS/ STAT User's Guide, 1990). ${ }^{22}$ We calculated the univariate correlation between $\mathrm{BMD}$ and each variable mentioned above. All variables that showed association at a 0.1 significance level in the univariate analysis were included in the multivariate analysis. The variables remaining in the final model were based on the model's comparisons using the likelihood ratio test. The analyses were performed separately for femoral neck $\mathrm{T}$ and $\mathrm{Z}$ scores (age was not adjusted for $Z$ score since it was an age-adjusted value already). The residual values were obtained after the associated variables were taken into account. Such residual values (adjusted BMD) were used in the familial correlation estimation.

\section{Familial correlation and heritability estimation}

Familial correlations of adjusted bone density traits (using residual values, see "Adjustment of BMD-related traits") were calculated using the FCOR (Familial Correlation program of S.A.G.E. [Statistical Analysis for Genetic Epidemiology] ). ${ }^{23} \mathrm{Fa}-$ milial correlations were used to evaluate the familial aggregation of the quantitative traits. It was assumed that the correlation in blood relatives was higher than that of the random sample (i.e., equal to 0 ) if the trait is determined by familial factors (including genetic and shared environmental factors). We calculated the correlations of mother-daughter pairs and sister-sister pairs by each of three weighting methods (equal weight to pairs, equal weight to pedigrees and equal weight to nuclear families). The $t$ test was used to assess whether these correlations were significantly greater than zero.

To assess the relative contribution of genetic and environmental factors to bone density and to the development of osteoporosis, we estimated the heritability $\left(\mathrm{h}^{2}\right)$ for each trait using variance component analysis as incorporated in the SOLAR software (Sequential Oligogenic linkage Analysis Routines). ${ }^{24}$ The $\mathrm{h}^{2}$ was defined as the ratio of genetic variance $\left(\mathrm{s}_{\mathrm{g}}{ }^{2}\right)$ over total phenotypic variance $\left(\mathrm{s}_{\mathrm{p}}{ }^{2}\right)$. The phenotypic variance may be due to genetic variance and shared or nonshared environmental variance. We calculated the variance components using the kinship matrix formulas using the observed maximum likelihood parameter estimates of the polygenic model. All variables significantly associated with BMD in the final model (see "Adjustment of BMD-related traits") were included as covariates in the model to estimate the $\mathrm{h}^{2}$. The likelihood ratio test was used to test the null hypothesis of no genetic determination: $\mathrm{h}^{2}=0$.

\section{RESULTS}

There were 61 independent Jewish families with a total of 166 female subjects in our sample. Most families (78.7\%) had 2 to 4 individuals. Eighty seven (52.4\%) subjects were the firstdegree relatives of probands. The average age of all study subjects was 54.3 years, ranging from 21 to 89 years. Table 1 shows the distribution of potential risk factors for osteoporosis among probands, first-degree relatives, and other relatives.

\section{Factors influencing the BMD in Jewish families}

Using univariate analysis, age, BMI, smoking, drinking, estrogen use, and serum measurement of albumin and magnesium were each significantly associated with femoral neck BMD T-scores, whereas only BMI was significantly associated with age-adjusted femoral neck BMD Z-scores. After all these significant variables were included in the multivariate analysis, only age $(P<0.0001)$, BMI $(P<0.0001)$, and albumin $(P=$ 0.055 ) remained statistically significant for femoral neck BMD T-scores. Therefore only age, BMI, and albumin were used as covariates for femoral neck BMD T-scores in the later analyses.

\section{Familial correlation}

Table 2 shows the familial correlation of the adjusted BMD traits in these Jewish families. Because three different weighting methods gave similar results, the results from equal pairs are summarized in Table 2. The correlation of femoral neck (both $\mathrm{T}$ score and $\mathrm{Z}$ score) between sister-sister pairs were significantly greater than the null hypothesis $(r=0)$ (all $r \geq$ 0.36 , all $P<0.01)$.

\section{Heritability estimation}

Table 3 shows the upperbound heritability estimates of each trait in these Jewish families. The heritability estimates for the 
Table 1

Risk factor distribution in proband and relatives ${ }^{a}$

\begin{tabular}{|c|c|c|c|}
\hline Factors & $\begin{array}{l}\text { Proband } \\
(N=61)\end{array}$ & $\begin{array}{l}\text { First-degree relatives } \\
\qquad(N=87)\end{array}$ & $\begin{array}{l}\text { Other relatives } \\
\quad(N=18)\end{array}$ \\
\hline Age & $61.0( \pm 10.7)$ & $49.0( \pm 13.8)$ & $57.4( \pm 17.0)$ \\
\hline BMI & $22.5( \pm 3.0)$ & $23.9( \pm 4.5)$ & $25.5( \pm 5.8)$ \\
\hline Smoking & $0 \%$ & $9.2 \%$ & $5.6 \%$ \\
\hline Drinking & $36.1 \%$ & $32.2 \%$ & $11.1 \%$ \\
\hline Estrogen use & $46.2 \%$ & $30.0 \%$ & $40.4 \%$ \\
\hline \multicolumn{4}{|l|}{ Serum biochemistries } \\
\hline Calcium & $9.1( \pm 0.4)$ & $9.0( \pm 0.4)$ & $9.0( \pm 0.3)$ \\
\hline 25-hydroxyvitamin D & $27.8( \pm 7.3)$ & $26.5( \pm 9.7)$ & $23.1( \pm 7.7)$ \\
\hline iPTH & $24.0(10,69)$ & $28.0(10,123)$ & $26.5(10,50)$ \\
\hline Creatinine & $0.6(0.4,1)$ & $0.6(0.4,1.3)$ & $0.6(0.4,0.7)$ \\
\hline Osteocalcin & $4.8(1.6,14)$ & $6.7(1.4,23)$ & $4.2(1.4,14)$ \\
\hline Bone-specific alkaline phosphatase & $7.9(2,15)$ & $8.2(4.1,22)$ & $9.3(4.5,17)$ \\
\hline Thyroid stimulating hormone & $1.30(0.02,4.10)$ & $1.20(0.02,7.90)$ & $1.65(0.67,3.80)$ \\
\hline Albumin & $4.4(3.8,4.9)$ & $4.5(3.5,5.0)$ & $4.2(3.9,4.9)$ \\
\hline Magnesium & $2.2(1.7,2.8)$ & $2.1(1.8,2.8)$ & $2.1(1.7,2.5)$ \\
\hline \multicolumn{4}{|l|}{ Urine biochemistries } \\
\hline Calcium & $5.7(0.5,30.2)$ & $6.0(0.6,49.2)$ & $9.6(1.0,24.4)$ \\
\hline Creatinine & $54(9,178)$ & $86(15,283)$ & $86(17,206)$ \\
\hline N-telopeptide & $24(8,94)$ & $31(9,109)$ & $34(17,74)$ \\
\hline \multicolumn{4}{|l|}{$\mathrm{BMD}$ trait by $\mathrm{DEXA}^{b}$} \\
\hline Femoral neck T score & $-2.31( \pm 0.76)$ & $-1.44( \pm 1.05)$ & $-1.65( \pm 1.00)$ \\
\hline Femoral neck Z score & $-0.93( \pm 0.64)$ & $-0.60( \pm 0.88)$ & $-0.35( \pm 0.84)$ \\
\hline
\end{tabular}

${ }^{a}$ For quantitative traits with a normal distribution, we calculated the mean $( \pm \mathrm{SD})$; for those traits nonnormally distributed, we state the median and range (minimum, maximum) values.

${ }^{b}$ Dual energy x-ray absorptiometry (DEXA) score normalized to a normative population at peak bone mass ( $\mathrm{T}$ score) and in same decade of life (Z score).

Table 2

Familial correlations for adjusted bone mineral density (BMD) traits according to equal pairs analysis

\begin{tabular}{lcc}
\hline BMD trait by DEXA $^{a}$ & $\begin{array}{c}\text { Mother-Daughter Paris } \\
(N=54) \\
\text { correlation }(\mathrm{SE})\end{array}$ & $\begin{array}{c}\text { Sister-Sister Pairs } \\
(N=64) \\
\text { correlation }(\mathrm{SE})\end{array}$ \\
\hline Femoral neck T & $0.37(0.14)^{b}$ & $0.37(0.12)^{b}$ \\
Femoral neck Z & $0.33(0.14)^{b}$ & $0.36(0.12)^{b}$ \\
\hline
\end{tabular}

${ }^{a}$ Dual energy $\mathrm{x}$-ray absorptiometry (DEXA) score normalized to controls at peak bone mass ( $\mathrm{T}$ score) and in same decade of life ( $\mathrm{Z}$ score).

${ }^{b} P<0.01$

left femoral neck $\mathrm{T}$ and $\mathrm{Z}$ DEXA scores were 0.73 and 0.67 , respectively, and highly significant (both $P<0.001$ ).

\section{DISCUSSION}

We conducted a study of females of Ashkenazi Jewish ancestry to assess the genetic determination of osteoporosis susceptibility in this population. After taking into account a large
Table 3

Heritability estimates for bone mineral density (BMD) in Ashkenazi Jewish families

\begin{tabular}{lccc}
\hline BMD trait by DEXA $^{a}$ & Heritability (SE) & Covariates & $P$ value \\
\hline Femoral neck T & $0.73(0.19)$ & age, BMI, albumin & $<0.001$ \\
Femoral neck Z & $0.67(0.20)$ & BMI & $<0.001$ \\
\hline
\end{tabular}

${ }^{a}$ Dual energy $\mathrm{x}$-ray absorptiometry (DEXA) score normalized to controls at peak bone mass (T score) and in same decade of life ( $\mathrm{Z}$ score).

number of potential risk factors influencing BMD, we observed significant familial resemblance among females within the family and obtained highly significant heritability estimates of BMD. The results demonstrate a strong genetic component $\left(\mathrm{h}^{2}=0.67 \sim 0.73\right)$ to the determination of BMD of the hip, specifically at the femoral neck in this ethnic group.

Familial resemblance might be due to genes or to shared environmental factors within families. ${ }^{25}$ Although some common environmental factors may be responsible for the familial resemblance, such as smoking status, alcohol consumption, 
estrogen usage, we found no association between these factors and BMD. After adjusting for the previously stated potential risk factors, our estimate of correlation between mothers and daughters was 0.33 for the femoral neck, a finding that is consistent with the findings in studies of healthy ${ }^{12}$ and osteoporotic $^{26}$ mothers and their daughters. The sister-sister correlation we observed was higher than a recent study, in which Baudoin et al. ${ }^{25}$ reported a correlation of 0.16 among sibs for femoral neck.

The estimates of heritability for BMD are relatively high in most twin studies $\left(\mathrm{h}^{2}>0.8\right)$. The assumption in twin studies is that the degree to which monozygotic (MZ) twins share a common environment is the same as that for dizygotic (DZ) twins. This is rarely the case and often leads to overestimates of heritability. ${ }^{27}$ Our $\mathrm{h}^{2}$ estimates of 0.73 and 0.67 for the femoral neck $\mathrm{T}$ and $\mathrm{Z}$ scores, respectively, fall in the middle range of $\mathrm{h}^{2}$ estimates obtained from twin studies. ${ }^{7-10,12}$ In addition, two family studies reported the heritability of BMD in Caucasian populations that were lower than that reported from the twin studies. Danielson et al. ${ }^{28}$ found the heritability estimates ranged from 0.50 to 0.63 , whereas Deng and his colleagues ${ }^{29}$ estimated that heritability at the hip was 0.65 . Although our $\mathrm{h}^{2}$ seems to be greater than those previously reported $h^{2}$ from family studies, such difference may not be statistically significant. In general, the majority of heritability estimates for BMD are in the range of 0.60 to 0.70 , which is at the higher end for various common complex traits.

The limitations of our study should be noted. Although the bias of common familial environmental effects has been reported as being small, ${ }^{30}$ it is noteworthy that our data were obtained from a single ethnic group among whom cultural background and environmental conditions were generally similar so that the observed heritability may be overestimated. In addition, our sample size is still modest. The impact of dietary differences and exercise on BMD was also not accounted for in our study. Two studies, a female twin study by Slemenda et al. ${ }^{10}$ and a male-female family study by Baudoin et al., ${ }^{25}$ evaluated the genetic and environmental effects on BMD by comparing the results before and after adjustment for environmental factors including dietary calcium intake and physical activity. The female twin study of Slemenda ${ }^{10}$ is the more informative of the two, demonstrating increased heritability estimates for hip BMD after the adjustment for environmental factors. The smaller male-female family study of Baudoin ${ }^{25}$ in the general French population showed that adjustment for environmental factors did not change the significant interclass correlations in femoral neck BMD among the families of male probands. In that study, a significant interclass correlation in femoral neck BMD was uncovered between the children of female probands and a previously significant interclass variation between the proband and their siblings was lost after adjustment for environment. Thus, unmeasured dietary and physical activities in our samples may not have had significant effect on the estimate of heritability of BMD. The accuracy of BMD as measured by DEXA in predicting the risk of osteoporotic fractures also warrants caution. It is important to recog- nize that fracture risk is multifactorial. The likelihood of a fracture depends on bone strength as well as the forces applied. ${ }^{31}$ Diminished bone strength is composed of abnormalities of bone quantity (mass, mineral density, and size) and quality (macro- and microarchitecture, bone turnover, material properties such as microdamage, and collagen cross-linking). ${ }^{32}$ Furthermore, genes regulating bone structure may differ than those regulating BMD. ${ }^{33}$

Osteoporosis is an oligogenic disease and BMD is a complex trait. ${ }^{34}$ It is presumed that multiple genes contribute to the variation in BMD. Genome-wide linkage screens conducted in humans and animals have reported linkage of femoral neck and lumbar spine BMD to chromosomes 1p, 2p, 4q, 5q, 6p, $11 \mathrm{q}, 13 \mathrm{q}$, and $22 \mathrm{q} \cdot{ }^{35-38}$ Our study is the first to describe the heritability of low BMD in Ashkenazi Jewish females. The relative homogeneity and the high estimates of heritability of BMD present in this population, particularly at the femoral neck, may prove valuable for the identification of site-specific osteoporosis susceptibility loci in future linkage and gene mapping studies.

\section{ACKNOWLEDGMENTS}

This work was supported in part by grants from the NIH (RR00425), the Cedars-Sinai Board of Governors' Chair in Medical Genetics and Women's Guild of Cedars-Sinai Medical Center.

\section{References}

1. Melton JL III. How many women have osteoporosis now? J Bone Miner Res 1995;2: 175-177.

2. Ray NF, Chan JK, Thamer M, Melton LJ III. Medical expenditures for the treatment of osteoporotic fractures in the United States in 1995: report from the National osteoporosis Foundation. J Bone Miner Res 1997;1:24-35.

3. Osteoporosis Prevention, Diagnosis, and Therapy. NIH Consensus Statemen 17(2), March 27, 2000, 1-26.

4. Raisz LG. The osteoporosis revolution. Ann Intern Med 1997;126:458-462.

5. Eisman JA. Vitamin D receptor gene alleles and osteoporosis; an affirmative view. J Bone Miner Res 1995;1:1289-1293.

6. Garnero P, Arden NK, Griffiths G, Delas Pd, Spector TD. Genetic influence on bone turnover in postmenopausal twins. J Clin Endocrinol Metab 1996;81:140-146.

7. Howard GM, Nguyen TV, Harris M, Kelly PJ, Eisman JA. Genetic and environmental contributions to the association between quantitative ultrasound and bone mineral density measurements: A twin study. J Bone Miner Res 1998;13:1318-1327.

8. Arden NK, Baker J. Hogg C, Baan K, Spector TD. The heritability of bone mineral density, ultrasound of the calcaneus and hip axis length: A study of postmenopausal twins. J Bone Miner Res 1996;11:530-534.

9. Popock NA, Eisman JA, Hopper JL, Yeates MG, Sambrook PN, Eberl S. Genetic determinants of bone mass in adults: A twin study. J Clin Invest 1987;80:706-710.

10. Slemenda CW, Christian JC, Williams CJ, Norton JA, Johnson CC Jr. Genetic determinants of bone mass in adult women: a re-evaluation of the twin model and the potential important of gene interaction on heritability estimates. J Bone Miner Res 1991;6:561-567.

11. Dequeker J. Nijs J, Verstraeten A, Geusens P, Gevers G. Genetic determinants of bone mineral content at the spine and radius: a twin study. Bone 1987;8:207-209.

12. Krall EA, Dawson-Hughes B. Heritable and life-style determinants of bone mineral density. J Bone Miner Res 1993;8:1-9.

13. Guenguen R, Jouanny P. Guillemin F, Kuntz C, Pourel J, Siest G. Segregation analysis and variance components analysis of bone mineral density in healthy families. J Bone Miner Res 1995;12:2017-2022.

14. Nordstrom P, Lorentzon R. Influence of heredity and environment on bone density in adolescent boys: a parent-offspring study. Osteo Int 1999;10:271-277.

15. Lau EMC, Suriwongpaisal P, Lee JK, Das De S, Festin MR, Saw SM et al. Asian Osteoporosis study. J Bone Miner Res 2001;6:572-580.

16. Makin M. Osteoporosis and proximal femoral fractures in the female elderly of Jerusalem. Clin Orthop 1987;218:19-23. 
17. Henderson LB, Adams JS, Goldstein DR, Braunstein GB, Rotter JI, Scheuner MT. A familial risk profile for osteoporosis. Genetic Med 2000;2:222-225.

18. Kleerekoper M, Nelson DA, Flynn MJ, Pawluszka AS, Jacobsen G, Peterson EL. Comparison of radiographic absorptiometry with dual-emergy $\mathrm{x}$-ray absorptiometry and quantitative computed tomography in normal older white and black women. J Bone Miner Res 1994;9:1745-1749.

19. Tobias JH, Cook DG, Chambers TJ, Dalzell N. A comparison of bone mineral density between Caucasian, Asian and Afro-Caribbean women. Clin Sci 1994;87:587591.

20. Cauley JA, Gutai JP, Juller LH, Scott J, Nevitt MC. Black-white differences in serum sex hormones and bone mineral density. Am J Epidemiol 1994;139:1035-1046.

21. Adams JS, Lee G. Gains in bone mineral density with resolution of vitamin D intoxication. Ann Intern Med 1997;127:203-206.

22. SAS Institute Inc. SAS/STAT User's Guide [Statistical Analysis Software (SAS)]. Version 6.12. Cary: SAS Institute Inc, 1990.

23. Department of Epidemiology, and Biostatistics, Case Western Reserve University, Cleveland. Statistical Analysis for Genetic Epidemiology [Familial Correlation (FCOR)]. Version 3.1. Cleveland: Case Western Reserve University, 1997.

24. Almasy L, Blangero J. Multipoint quantitative-trait linkage analysis in general pedigrees. Am J Hum Genet 1998;62:1198-1211.

25. Baudoin C, Cohen-Solal ME, Beaudreuil J, De Vernejoul MC. Genetic and environmental factors affect bone density variances of families of men and women with osteoporosis. J Clin Endocrinol Metab 2002;87:2053-2059.

26. Seeman EM, Hopper JL, Bach LA, Cooper ME, Parkinson E, McKay J et al. Reduced bone mass in daughters of women with osteoporosis. N Engl J Med 1989;320:554-558.

27. Peacock M, Turner CH, Econs MJ, Foroud T. Genetics of osteoporosis. Endocr Rev 2002;23:303-326.

28. Danielson ME, Cauley JA, Baker CE, Newman AB, Dorman JS, Towers JD et al. Familial resemblance of bone mineral density (BMD) and calcaneal ultrasound attenuation: The BMD in mothers and daughters study. J Bone Miner Res 1999;14:102-110.
29. Deng HW, Mahaney MC, Williams JT, Li J, Conway T, Davies MK et al. Relevance of the genes for bone mass variation to susceptibility to osteoporotic fractures and its implications to gene search for complex human diseases. Genet Epidemiol 2002;22: $12-25$.

30. Deng HW, Stegman MR, Davies KM, Conway T, Recker RR. Genetic determination of variation and covariation of peak bone mass at the hip and spine. JClin Densitom 1999;2:251-263.

31. Nguyen T, Sambrook P, Kelly P, Jones G, Lord S, Freund J et al. Prediction of osteoporotic fractures by postural instability and bone density. BMJ 1993;307:111115.

32. Chestnut CH III, Rosen CJ. Reconsidering the effects of antiresorptive therapies in reducing osteoporotic fracture. J Bone Miner Res 2001;16:2163-2172.

33. Koller DL, Liu G, Econs MJ, Hui SL, Morin PA, Joslyn G et al. Genome screen for quantitative trait loci underlying normal variation in femoral structure. $J$ Bone Miner Res 2001;16:985-991.

34. Foroud T, Econs MJ, Johnston CC. Genetics in osteoporosis. In: King RA, Rotter JI, Motulsky AG, editors. The genetic basis of common diseases, 2nd ed. New York: Oxford University Press, 2002:510-517.

35. Klein RF, Mitchell SR, Phillips RJ, Belknap JK, Orwoll ES. Quantitative trait loci affecting peak bone mineral density in mice. J Bone Miner Res 1998;13:1648-1656.

36. Koller DL, Econs MJ, Morin PA, Christian JC, Hui SL, Parry P et al. Genome screen for QTLs contributing to normal variation in bone mineral density and osteoporosis. J Clin Endocrinol Metab 2000;85:3116-3120.

37. Mahaney MC, Morin P, Rodriquez LA, Newman DE, Rogers JA. A quantitative trait locus on chromosome 11 may influence bone mineral density at several sites: Linkage analyses in pedigreed baboons. J Bone Miner Res 1997;12(suppl 1):64.

38. Devoto M, Specchia C, Li H-H, Caminis J, Tenenhouse A, Rodriguez H et al. Variance component linkage analysis indicates a QTL for femoral neck bone density on chromosome 1p36. Hum Mol Genet 2001;10:2447-2452. 